\title{
Mobilization of arsenic from contaminated sediment by anionic and nonionic surfactants
}

\author{
Chuan Liang, Xianjia Peng* \\ Beijing Key Laboratory of Industrial Wastewater Treatment and Reuse, Research Center for Eco-Environmental Sciences, Chinese Academy of \\ Sciences, Beijing 100085, China. E-mail: liangchuan12@mails.ucas.ac.cn \\ Key Laboratory of Drinking Water Science and Technology, Research Center for Eco-Environmental Sciences, Chinese Academy of Sciences, \\ Beijing 100085, China
}

\section{A R T I C L E I N F O}

Article history:

Received 31 March 2016

Revised 13 October 2016

Accepted 14 October 2016

Available online 1 November 2016

\section{Keywords:}

Surfactants

Arsenic

Iron

Sediment

Mobilization

\begin{abstract}
A B S T R A C T
The increasing manufacture of surfactants and their wide application in industry, agriculture and household detergents have resulted in large amounts of surfactant residuals being discharged into water and distributed into sediment. Surfactants have the potential to enhance arsenic mobility, leading to risks to the environment and even human beings. In this study, batch and column experiments were conducted to investigate arsenic mobilization from contaminated sediment by the commercial anionic surfactants sodium dodecylbenzenesulfonate (SDBS), sodium dodecyl sulfate (SDS), sodium laureth sulfate (AES) and nonionic surfactants phenyl-polyethylene glycol (Triton X-100) and polyethylene glycol sorbitan monooleate (Tween-80). The ability of surfactants to mobilize arsenic followed the order AES $>$ SDBS $>$ SDS $\approx$ Triton $\mathrm{X}-100>$ Tween 80 . Arsenic mobilization by AES and Triton $\mathrm{X}-100$ increased greatly with the increase of surfactant concentration and $\mathrm{pH}$, while arsenic release by SDBS, SDS and Tween- 80 slightly increased. The divalent ion $\mathrm{Ca}^{2+}$ caused greater reduction of arsenic mobilization than $\mathrm{Na}^{+}$. Sequential extraction experiments showed that the main fraction of arsenic mobilized was the specifically adsorbed fraction. Solid phase extraction showed that arsenate $(\mathrm{As}(\mathrm{V}))$ was the main species mobilized by surfactants, accounting for $65.05 \%-77.68 \%$ of the total mobilized arsenic. The mobilization of arsenic was positively correlated with the mobilization of iron species. The main fraction of mobilized arsenic was the dissolved fraction, accounting for $70 \%$ of total mobilized arsenic.

C 2016 The Research Center for Eco-Environmental Sciences, Chinese Academy of Sciences.
\end{abstract}

Published by Elsevier B.V.

\section{Introduction}

Arsenic is ubiquitously distributed in aquatic environments, soil and sediment. Both natural phenomena including weathering and biological activity and anthropogenic processes such as mining activities, fossil fuel combustion and use of pesticides contribute to the input of arsenic in the environment (Cullen and Reimer, 1989). The release of arsenic from sediment has attracted much attention, as the process could directly elevate arsenic concentrations in surface and ground water, causing severe risks to organisms and human health. The arsenic mobilized from contaminated sediment has become the major source of arsenic in groundwater in many countries and regions, where the concentrations have often exceeded the WHO drinking water limit of $10 \mu \mathrm{g} / \mathrm{L}$ (Islam et al., 2004; Nickson et al., 2000; Polizzotto et al., 2008). The predominant species of arsenic in contaminated sediment include arsenate $(\mathrm{As}(\mathrm{V}))$, arsenite $(\mathrm{As}(\mathrm{III}))$ and organic arsenic

\footnotetext{
* Corresponding author. E-mail: xjpeng@rcees.ac.cn (Xianjia Peng).
} 
compounds, among which As(III) is more toxic and mobile than $\mathrm{As}(\mathrm{V})$ and organic complex fractions. Mobilization of arsenic by coexisting substances is an important factor contributing to arsenic release to water. The most widely studied substances relating to the mobilization of arsenic so far have been natural organic matters. In addition, coexisting anions such as $\mathrm{PO}_{4}^{3-}$ and $\mathrm{SO}_{4}^{2-}$ are well-known substances contributing to the displacement of arsenic from sediment (Bauer and Blodau, 2006; Guo et al., 2011; Mladenov et al., 2010; Routh et al., 2007; Sharma et al., 2011; Wang and Mulligan, 2009a, 2009b).

Surfactants are groups of amphiphilic compounds that consist of both polar hydrophilic groups and hydrophobic hydrocarbon chains. Due to their ability to reduce interfacial tension, surfactants are widely used in detergent products, mining activities and enhanced oil recovery (Basar et al., 2004; Bennie et al., 1997; Céspedes et al., 2008; Clara et al., 2007; Zhang et al., 2013). This wide range of applications leads to large amounts of surfactant residuals being discharged to water treatment plants or directly into the water environment. Different concentrations of surfactants have been detected in wastewater, sewage treatment plant effluents, water bodies and sediments. For example, the concentrations of some linear alkylbenzenesulfonates (LAS) in wastewater and treated sludge have been reported to reach $1090 \mu \mathrm{g} / \mathrm{L}$ and $30,200 \mathrm{mg} / \mathrm{kg}$, respectively (Lara-Martín et al., 2006, 2008; Ying et al., 2002). In natural water, levels of LAS were found to be up to $416 \mu \mathrm{g} / \mathrm{L}$ (Lara-Martín et al., 2006, 2008; Marcomini et al., 2000; Shalaby, 2007; Ying et al., 2002; Ying, 2006; Zgoła-Grześkowiak et al., 2009). In addition, surfactants are also efficient at removing organic matters and heavy metals from contaminated soil by solubilization and ligand exchange (Mulligan et al., 2001a; Mulligan, 2005, 2009; West and Harwell, 1992). This indicates the potential of surfactants to enhance the mobility of coexisting organic matters and trace metals from sediments or soil. Previous research has reported that arsenic in mine tailings could be greatly mobilized by biosurfactants (Wang and Mulligan, 2009c). In our previous research, the anionic surfactant sodium dodecyl benzene sulfonate (SDBS) and nonionic surfactant Triton X-100 were found to reduce arsenic adsorption onto ferrihydrite and enhance arsenic transport through columns packed with ferrihydrite-coated sand (Liang et al., 2016). However, there has been a lack of study on the potential of commercial surfactants to mobilize arsenic. Thus, in the current study, five commercial surfactants were chosen to evaluate the potential of surfactants to mobilize arsenic from contaminated sediment. SDBS, sodium dodecyl sulfate (SDS) and sodium laureth sulfate (AES) are the most widely used anionic surfactants. The nonionic surfactants phenyl-polyethylene glycol (Triton X-100) and polyethylene glycol sorbitan monooleate (Tween-80) are also widely used in industrial applications. Elucidating the effects of surfactants on arsenic mobilization from sediment is of great importance in understanding the processes causing arsenic release to water. In this investigation, batch and column tests were carried out to study the potential of the five surfactants to mobilize arsenic from contaminated sediment. The effects of surfactant type, surfactant concentration, $\mathrm{pH}$, coexisting cations and time on arsenic mobilization were evaluated. Sequential extraction procedures (SEPs), solid phase extraction (SPE), ultrafiltration and dialysis tests were conducted to investigate the speciation of released arsenic. Mechanisms relating to arsenic mobilization by surfactants were also discussed.

\section{Materials and methods}

\subsection{Sediment sample}

The sediment sample was collected from the Zi River near a tin mining site in Lengshuijiang City, Hunan Province, China. The sediment sample was freeze-dried, ground and passed through a 100-mesh sieve previous to use. For arsenic and metal content measurement, the sediment was first digested using the CEM Mars 6 digestion system. The total concentrations of arsenic and metals in the solution from digestion were measured using inductively coupled plasma mass spectrometry (ICP-MS, 7500a, Agilent, USA). The specific surface area of the sediment particles was obtained using the BET- $\mathrm{N}_{2}$ adsorption method. Content of organic matter was determined according to the weight loss after calcination at $550^{\circ} \mathrm{C}$ for $4 \mathrm{hr}$. The $\mathrm{pH}$ of a mixture of $10.0 \mathrm{~g}$ of sample in $50 \mathrm{~mL}$ ultra-pure water was employed as the sediment $\mathrm{pH}$.

\subsection{Surfactants}

Anionic surfactants SDBS $\left(\mathrm{C}_{18} \mathrm{H}_{29} \mathrm{SO}_{3} \mathrm{Na}\right)$, SDS $\left(\mathrm{C}_{12} \mathrm{H}_{25} \mathrm{OSO}_{3} \mathrm{Na}\right)$ and AES $\left(\mathrm{C}_{14} \mathrm{H}_{33} \mathrm{O}_{3} \mathrm{SO}_{3} \mathrm{Na}\right)$ were purchased from Sino Pharm Chemical Reagents Co., China. Nonionic surfactants Triton $\mathrm{X}-100\left(\mathrm{C}_{14} \mathrm{H}_{22} \mathrm{O}\left(\mathrm{C}_{2} \mathrm{H}_{4} \mathrm{O}\right)_{10}\right)$ and Tween-80 $\left(\mathrm{C}_{64} \mathrm{H}_{125} \mathrm{O}_{26}\right)$ were purchased from Sigma Aldrich, USA. All chemicals were of analytical grade and used without further purification. The contents of arsenic in the surfactants were negligible.

\subsection{Batch experiments}

Batch experiments were conducted to investigate arsenic mobilization from sediment by surfactants at various concentrations, over a range of $\mathrm{pH}$ conditions and in the presence of different metal ions. The mobilization of iron by surfactants was also evaluated in batch experiments. $2.0 \mathrm{~g}$ sediment samples and $40 \mathrm{~mL}$ solutions with prescribed surfactant concentrations, $\mathrm{pH}$ values, and $\mathrm{Na}^{+}$or $\mathrm{Ca}^{2+}$ concentrations were added to a batch of $50 \mathrm{~mL}$ centrifuge tubes. The tubes were shaken at $150 \mathrm{r} / \mathrm{min}$ and $25^{\circ} \mathrm{C}$ for $24 \mathrm{hr}$. Then the suspensions were centrifuged at $8000 \mathrm{r} / \mathrm{min}$ for $15 \mathrm{~min}$ and the supernatants were collected for arsenic and/or iron concentration analysis.

The time dependence of arsenic mobilization was studied in batch tests. 5.0 g sediment samples and $500 \mathrm{~mL}$ of $100 \mathrm{mg} / \mathrm{L}$ surfactant solutions were added to $500 \mathrm{~mL}$ bottles. The suspensions were continuously stirred at $25^{\circ} \mathrm{C}$. The initial $\mathrm{pH}$ of the suspensions was adjusted to 7.0 and readjusted to 7.0 at prescribed time intervals using $\mathrm{HCl}$ or $\mathrm{NaOH}$ solutions. For comparison, bottles containing $5.0 \mathrm{~g}$ sediment samples and $500 \mathrm{~mL}$ deionized water were stirred under the same conditions. At prescribed time intervals, $2.0 \mathrm{~mL}$ aliquots of the suspensions were taken and centrifuged at $8000 \mathrm{r} / \mathrm{min}$ for 15 min. The supernatant was collected for arsenic concentration analysis. In the batch tests, all the solutions were 
prepared using deionized water through which ultrapure nitrogen gas was bubbled for $30 \mathrm{~min}$, and the sampling processes were carried out in a nitrogen gas atmosphere.

\subsection{Column experiments}

Columns used in the experiments were $2.0 \mathrm{~cm}$ in diameter and $14.0 \mathrm{~cm}$ in length. Each column was packed with $26.0 \mathrm{~g}$ sediment sample. The porosity was measured at $41.6 \%$. The $\mathrm{pH}$ of the influents was adjusted to 7.0 using $\mathrm{HCl}$ or $\mathrm{NaOH}$ solutions. Influent solutions were pumped through the packed columns at a rate of $50 \mathrm{~mL} / \mathrm{hr}$. The duration of the column runs was 12 days. For arsenic concentration measurement, $2.0 \mathrm{~mL}$ aliquots of effluent were collected and centrifuged at $8000 \mathrm{r} / \mathrm{min}$ for $15 \mathrm{~min}$ at prescribed time intervals.

\subsection{Sequential extraction procedures (SEP)}

Prior to the SEP analysis, the surfactant-treated sediment samples were prepared as follows: In $50 \mathrm{~mL}$ centrifuge tubes, $1.0 \mathrm{~g}$ sediment samples were mixed with $50 \mathrm{~mL} 100 \mathrm{mg} / \mathrm{L}$ surfactant solutions and shaken at $150 \mathrm{r} / \mathrm{min}$ at $25^{\circ} \mathrm{C}$ for $24 \mathrm{hr}$. Then the mixture was centrifuged at $8000 \mathrm{r} / \mathrm{min}$ for $15 \mathrm{~min}$ and the supernatant was removed. After that, the residual sediment was washed using $50 \mathrm{~mL}$ deionized water for $10 \mathrm{~min}$ and the mixture was centrifuged again at $8000 \mathrm{r} / \mathrm{min}$ for $15 \mathrm{~min}$. The supernatant was removed and the residual sediment was used for SEP analysis. Arsenic fractions in the raw and surfactant-treated sediment samples were analyzed using Wenzel's five-step sequential extraction method (Wenzel et al., 2001).

\subsection{SPE}

Speciation of arsenic mobilized by surfactants was evaluated with the SPE method using a Visiprep SPE device (Supelco, USA). Strong cation-exchange cartridges (LC-SCX, $500 \mathrm{mg} / 3 \mathrm{~mL}$ ) were obtained from Supelco, Canada. Strong anion-exchanges cartridges (LC-SAX, $500 \mathrm{mg} / 3 \mathrm{~mL}$ ) were purchased from VARIAN, USA. Before being used, the cartages were preconditioned with $50 \%$ methanol and deionized water. Supernatants from batch tests were used for the SPE extractions. For comparison, effluents collected from column experiments at $160 \mathrm{hr}$ were also employed for SPE study. A 3-mL sample solution was sequentially passed through the SCX cartridges and SAX cartridges at a flow rate of $0.5 \mathrm{~mL} / \mathrm{min}$. The SCX and SAX cartridges retained $\mathrm{As}(\mathrm{V})$ and organically associated arsenic, while As(III) remained in the effluents (Le et al., 2000; Yalcin and Le, 2001). Arsenate retained in the SAX cartridges was eluted using $3 \mathrm{~mL} 1 \mathrm{~mol} / \mathrm{L} \mathrm{HCl}$ solution at $0.5 \mathrm{~mL} / \mathrm{min}$. Another $3 \mathrm{~mL}$ $1 \mathrm{~mol} / \mathrm{L} \mathrm{HCl}$ solution was then passed through the SAX cartridges to ensure complete elution of $\mathrm{As}(\mathrm{V})$.

\subsection{Dialysis and ultra-filtration study}

To determine the fractions of arsenic (free anion fraction, iron-associated fraction or organic matter-associated fraction) mobilized by surfactants, dialysis and ultrafiltration were employed to separate the free ionic fractions and complexed fractions of arsenic and iron (Sharma et al., 2011). Concentrations of mobilized arsenic and iron were compared before and after dialysis and ultrafiltration studies. Solutions containing mobilized arsenic and iron were prepared in batch tests. For dialysis, 2.0 g sediment samples were shaken in $50 \mathrm{~mL} 500 \mathrm{mg} / \mathrm{L}$ surfactant solutions for $16 \mathrm{hr}$. The mass ratio between surfactants and sediment was $12.5 \mathrm{mg} / \mathrm{g}$. For ultrafiltration, $25.0 \mathrm{~g}$ sediment samples were stirred in $500 \mathrm{~mL} 50 \mathrm{mg} / \mathrm{L}$ surfactant solutions for $16 \mathrm{hr}$. The mass ratio between surfactants and sediment was $1 \mathrm{mg} / \mathrm{g}$.

The 1000 Da Biotech cellulose ester (CE) dialysis membrane bags used in this study were purchased from Spectrum Lab Co., USA. In each dialysis membrane bag, $5 \mathrm{~mL}$ solution was added and the bag was immersed in $150 \mathrm{~mL}$ ultra-pure water that was continuously stirred using a magnetic stirrer. Water was replaced every $6 \mathrm{hr}$ until there was no arsenic or iron detected. The driving force of dialysis is the concentration difference between the solutions in the dialysis bag and water outside of the bag. To accelerate this process, a larger mass ratio between surfactants and sediment was applied for the preparation of solutions for dialysis. After dialysis, $1 \mathrm{~mL}$ solution from the bag was taken and used for arsenic and iron concentration measurements.

For ultrafiltration, $200 \mathrm{~mL}$ solution was transferred into a $350 \mathrm{~mL}$ ultrafiltration system. The $1000 \mathrm{Da}$ ultrafiltration membrane was purchased from Millipore Co. United States. The ultrafiltration was processed under $0.4 \mathrm{MPa}$ using pure $\mathrm{N}_{2}$. The effluent was collected for arsenic and iron concentration analysis.

\section{Results and discussion}

\subsection{Arsenic mobilization by surfactants in batch experiments}

\subsubsection{Properties of the sediment sample}

The arsenic content of the sediment was $269.3 \pm 4.8 \mathrm{mg} / \mathrm{kg}$, suggesting that it could be an important source of arsenic contamination due to potential leaching processes. The contents of metals in the sediment are listed as follows: Fe: $616.6 \pm 8.5 \mathrm{mg} / \mathrm{kg}, \mathrm{Cu}: 19.2 \pm 1.1 \mathrm{mg} / \mathrm{kg}, \mathrm{Zn}: 69.7 \pm 2.9 \mathrm{mg} / \mathrm{kg}$ Cr: $106.5 \pm 5.3 \mathrm{mg} / \mathrm{kg}$. The mass content of organic matters was determined to be $5.8 \%$. In contaminated sediments, arsenic is generally associated with iron oxides or iron oxyhydroxides due to co-precipitation reactions (Cullen and Reimer, 1989; Garcia et al., 2010). This indicated that arsenic could be mobilized in water-soluble and specifically associated species. The sediment $\mathrm{pH}$ was 5.31, indicating the weakly acidic nature of the sediment. The specific surface area of the sediment particles was $11.6 \mathrm{~m}^{2} / \mathrm{g}$.

\subsubsection{Influence of surfactant concentration}

Mobilization of arsenic from the sediment by anionic and nonionic surfactants at various concentrations was investigated. By varying the concentrations of surfactants from 1 to $500 \mathrm{mg} / \mathrm{L}$, the mass ratio between surfactant and sediment was varied from 0.02 to $10 \mathrm{mg} / \mathrm{kg}$. For comparison, arsenic mobilization from sediment in deionized water was also investigated. The concentration of arsenic released by deionized water was $8.90 \mu \mathrm{g} / \mathrm{L}$. The mobilization of arsenic by surfactants at pH 7.0 is shown in Fig. 1. Concentrations of 

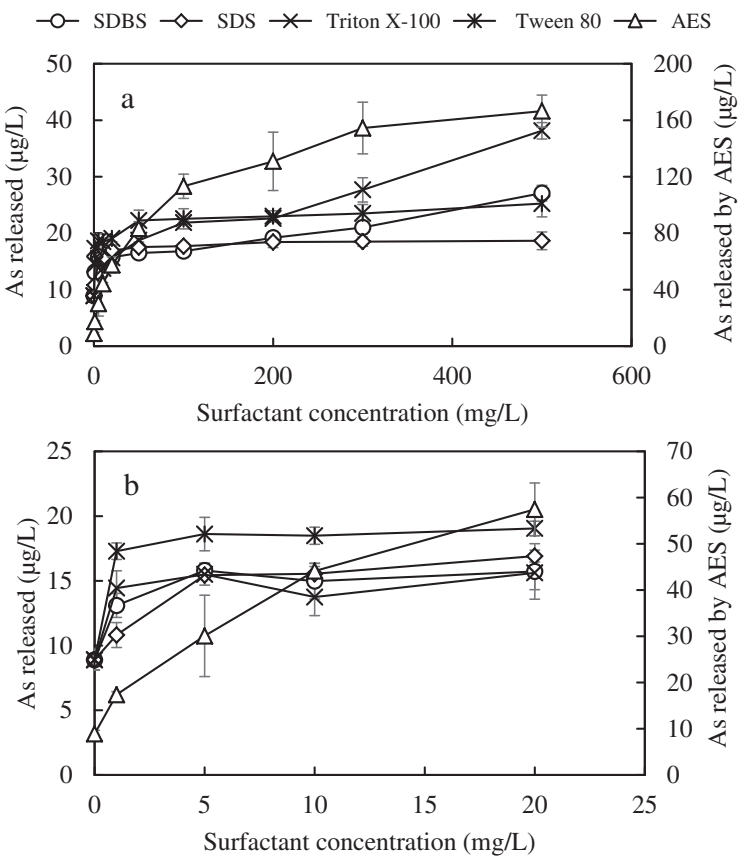

Fig. 1 - The mobilization of arsenic by surfactants in the overall concentration range of 0 to $500 \mathrm{mg} / \mathrm{L} \mathrm{(a)}$, and the effects of low concentrations of surfactant $(0-20 \mathrm{mg} / \mathrm{L})$ on the mobilization of arsenic (b). The experiments were conducted at $\mathrm{pH} 7.0$ and $25^{\circ} \mathrm{C}$. The concentration of the sediment was $50.0 \mathrm{~g} / \mathrm{L}$.

arsenic in $1 \mathrm{mg} / \mathrm{L}$ SDBS, SDS, AES, Triton X-100 and Tween 80 reached $13.10,10.82,17.34,14.44$ and $17.29 \mu \mathrm{g} / \mathrm{L}$, respectively, which was notably higher than the concentration of arsenic released in deionized water. When the concentration of surfactants was $5 \mathrm{mg} / \mathrm{L}$, as shown in Fig. 1b, the arsenic concentration exceeded the $10 \mu \mathrm{g} / \mathrm{L}$ limit for arsenic in drinking water in most cases. In addition, arsenic mobilization by the anionic surfactant AES was more remarkable than that by the other four surfactants. In the $10 \mathrm{mg} / \mathrm{L}$ AES solution, the concentration of mobilized arsenic reached $44.12 \mu \mathrm{g} / \mathrm{L}$. By comparing the molecular structures of the five surfactants, the polyoxyethylene groups and negatively charged sulfate groups of AES may contribute to the greater release of arsenic compared to the other four surfactants. For all five surfactants, arsenic mobilization increased significantly with the increase of surfactant concentration. It is well known that surfactants tend to be adsorbed onto sediment, and the adsorption amount increases with the increase of surfactant concentrations (Wang and Kwak, 1999; Yang et al., 2007, 2010; Zhang et al., 2011). Thus, in this study, surfactant adsorption onto sediment could lead to arsenic release by anionic exchange as well as reduction of interfacial tension. Adsorption of anionic surfactants could increase the negative charge on the sediment surface, which could also contribute to the release of arsenic from the particle surface.

In SDBS, AES and Triton X-100 solutions, mobilization of arsenic increased significantly with the increase of surfactant concentrations, while the mobilization of arsenic by SDS and Tween 80 reached a plateau after the concentrations of surfactants exceeded $50 \mathrm{mg} / \mathrm{L}$.

\subsubsection{Influence of $p H$}

Mobilization of arsenic from sediment by surfactants in the $\mathrm{pH}$ range from 3.0 to 10.0 is shown in Fig. 2. For the surfactants SDBS, SDS, Triton X-100 and Tween 80, mobilization of arsenic increased slightly with the increase of $\mathrm{pH}$ when $\mathrm{pH}$ was lower than 9.0. For AES, the increase of $\mathrm{pH}$ dramatically promoted arsenic mobilization. As one of the most important environmental factors, $\mathrm{pH}$ variations could affect arsenic mobilization by various mechanisms. The mobilization of arsenic by all five surfactants was larger than that by deionized water under all experimental $\mathrm{pH}$ conditions. The introduction of $\mathrm{OH}^{-}$could increase the replacement of arsenic from sediment. Increase of $\mathrm{pH}$ could also enhance the negative charge of the sediment particle surface, which could enhance the repulsion between arsenic species in the solution and the sediment surface (Rodríguez-Cruz et al., 2005; Rubinos et al., 2010; Rubio-Campos et al., 2010; Shen, 2000; Sugihara et al., 2008). However, previous research has reported that the increase of $\mathrm{pH}$ had a negative effect on the adsorption of anionic surfactants due to the reversion of the surface charge (Camacho et al., 1996; Huang and Van Benschoten, 2000; Li et al., 2012; Mushtaq et al., 2015). That indicated that the increase of $\mathrm{pH}$ could reduce the contribution of the adsorption of surfactants to the mobilization of arsenic, but the overall effect of increasing $\mathrm{pH}$ was to enhance the mobilization of arsenic.

\subsubsection{Influence of cations}

Arsenic mobilization from sediment by surfactants under the effect of metal ions was examined using the most prevalent monovalent and divalent cations, $\mathrm{Na}^{+}$and $\mathrm{Ca}^{2+}$. As shown in Fig. 3, both $\mathrm{Na}^{+}$and $\mathrm{Ca}^{2+}$ had little effect on the mobilization of arsenic in deionized water. $\mathrm{Na}^{+}$in the concentration range of 10-200 mg/L had little effect on the mobilization of arsenic by SDBS, SDS, Triton X-100 and Tween 80, while arsenic released by AES decreased under the influence of $\mathrm{Na}^{+}$when the concentration was higher than $100 \mathrm{mg} / \mathrm{L}$. Arsenic mobilization by all five surfactants dramatically decreased under the influence of $\mathrm{Ca}^{2+}$ in the concentration range of $2-80 \mathrm{mg} / \mathrm{L}$. The capacity of the anionic surfactant AES to mobilize arsenic was

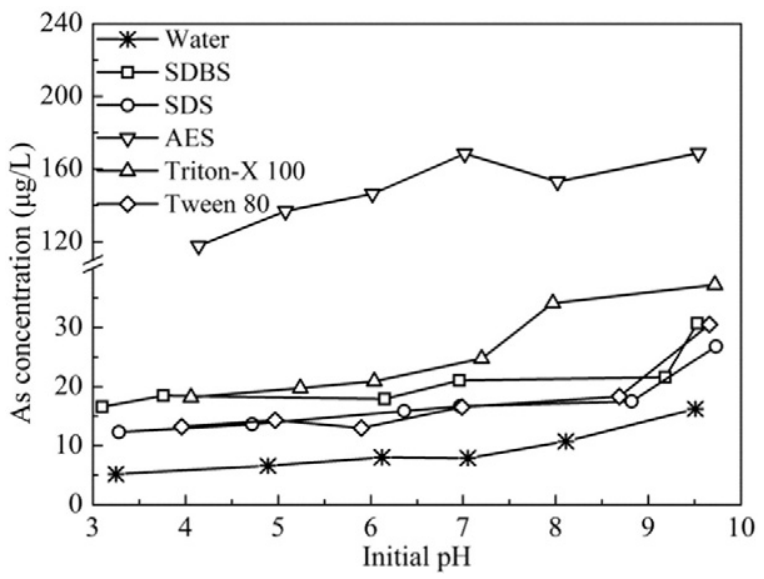

Fig. 2 - Influence of $\mathrm{pH}$ on the mobilization of arsenic from sediment by surfactants and deionized water at $25^{\circ} \mathrm{C}$. The concentration of surfactants and sediment was $100 \mathrm{mg} / \mathrm{L}$ and $50.0 \mathrm{~g} / \mathrm{L}$, respectively. 

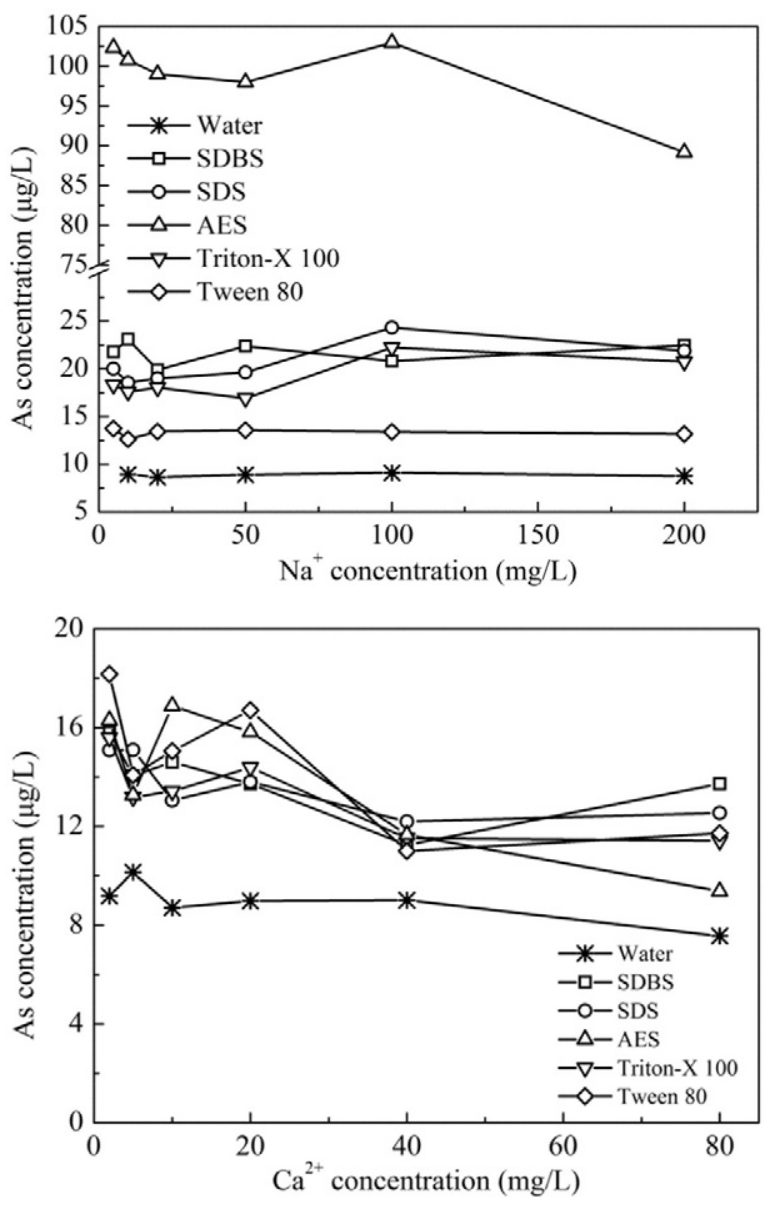

Fig. 3 - Influence of $\mathrm{Na}^{+}$and $\mathrm{Ca}^{2+}$ on the mobilization of arsenic from sediment by surfactants and deionized water at $\mathrm{pH} 7.0$ and $25^{\circ} \mathrm{C}$. The concentration of surfactants and sediment was $200 \mathrm{mg} / \mathrm{L}$ and $100 \mathrm{~g} / \mathrm{L}$, respectively.

hugely reduced by $\mathrm{Ca}^{2+}$ at low concentrations. For example, the equilibrium concentration of mobilized arsenic decreased from $113.20 \mu \mathrm{g} / \mathrm{L}$ to $16.30 \mu \mathrm{g} / \mathrm{L}$ in the presence of $2 \mathrm{mg} / \mathrm{L}$ AES when the $\mathrm{Ca}^{2+}$ concentration was $10 \mathrm{mg} / \mathrm{L}$. This indicated that the presence of cations mainly reduced the potential of surfactants to mobilize arsenic, which could be attributed to the increase of positive charge on the sediment particle surface. It can be seen from the results that metal ions had greater effects on anionic surfactants than on nonionic surfactants regarding arsenic mobilization. This was mainly due to the precipitation reactions of anionic surfactants in the presence of metal ions (Rao and He, 2006; Rosen and Kunjappu, 2012; Sanchez-Martin et al., 2008). In addition, the presence of metal ions could have negative effects on the adsorption of anionic surfactants onto the sediment particles (Li et al., 2012), which might partly contribute to the decreasing mobilization of arsenic from the sediment.

\subsubsection{Influence of time}

The time dependence of mobilization of arsenic by surfactants is shown in Fig. 4. The release of arsenic from sediment by SDBS, SDS, Triton X-100 and Tween 80 was divided into two

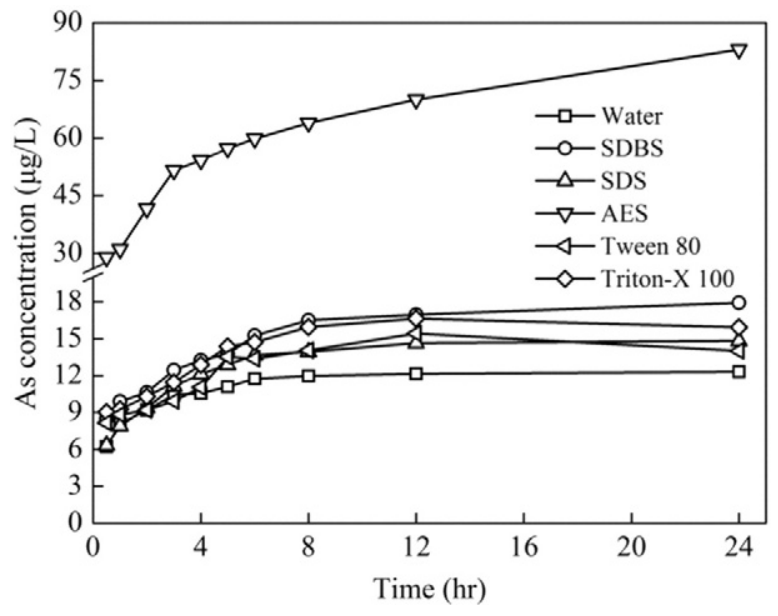

Fig. 4 - Influence of time on the mobilization of arsenic from sediment by surfactants at $\mathrm{pH} 7.0$ and $25^{\circ} \mathrm{C}$. The concentration of surfactants and sediment was $100 \mathrm{mg} / \mathrm{L}$ and $10 \mathrm{~g} / \mathrm{L}$, respectively.

stages: in the first $8 \mathrm{hr}$, arsenic release increased with time and achieved equilibrium after $12 \mathrm{hr}$. In AES solution, arsenic mobilization increased prominently in the first $4 \mathrm{hr}$, then increased slightly with time. In the experimental time scale of $24 \mathrm{hr}$, no mobilization equilibrium was achieved in the AES system, which indicated that compared to the other four surfactants, AES had greater potential for As mobilization from sediment over a long time period.

\subsection{Column study}

The experimental columns packed with sediment were used to simulate arsenic release in the environment under the flow of water containing surfactants. This is of environmental significance in assessing the risk of sediment as a source of arsenic in groundwater. As shown in Fig. 5, flushing by five surfactant solutions caused more arsenic release from sediment-packed

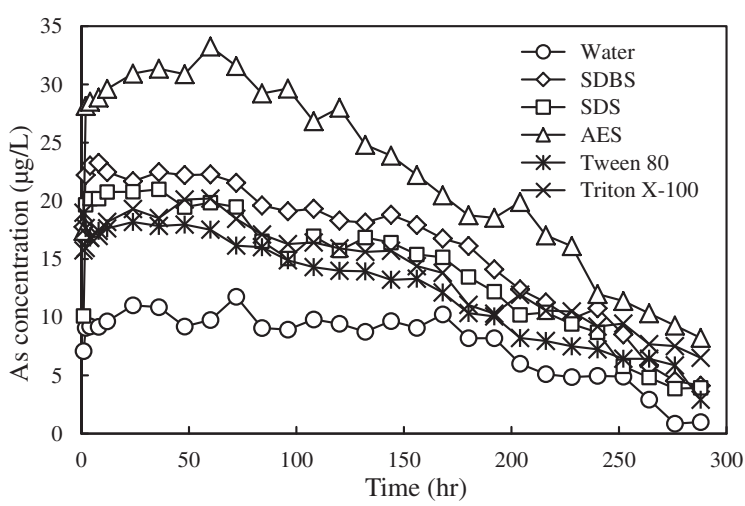

Fig. 5 - Release of As from sediment-packed columns by the flow of water and surfactant solutions at $\mathrm{pH} 7.0$ and $25^{\circ} \mathrm{C}$. The concentration of surfactants in the influents was $50 \mathrm{mg} / \mathrm{L}$ and the volumetric flow rate was $50.0 \mathrm{~mL} / \mathrm{hr}$. The packing amount of sediment was $26.0 \mathrm{~g}$. 
columns than water. Release of arsenic under the flow of surfactant solutions showed a period of rapid increase followed by slow decrease. This indicated that arsenic adsorbed on the external layer of the sediment surface was quickly eluted by the flow of surfactant solutions. However, the release of arsenic associated with the inner layer of sediment by surfactants slowed down with time. To quantitatively compare the dynamic mobilization of arsenic by the five anionic and nonionic surfactants, concentrations of arsenic in the effluents were measured as a function of time, and the cumulative release amounts of arsenic were calculated by integration using Origin 8.1. The integration formula is represented as follows:

$\mathrm{Q}=\int_{0}^{\mathrm{T}} \mathrm{C}(\mathrm{t}) \cdot v \cdot \mathrm{dt}$.

where, $Q(\mu \mathrm{g})$ is the calculated cumulative release amount of arsenic; $C(t)(\mu \mathrm{g} / \mathrm{L})$ is the arsenic concentration as a function of time; $v$ is the flow rate of surfactant solution, which was $50.0 \mathrm{~mL} / \mathrm{hr}$ in the present study; $\mathrm{T}(\mathrm{hr})$ is the elution time, $288 \mathrm{hr}$ in this study. Thus, according to the calculation, the amount of arsenic released by SDBS, SDS, AES, Triton X-100 and Tween 80 was 231.32, 202.71, 324.70, 202.67 and $177.39 \mu \mathrm{g}$, which was 2.06, $1.80,2.89,1.80$ and 1.58 times the amount of arsenic eluted by deionized water, respectively. It can be concluded that in elution systems, the potential of surfactants to mobilize arsenic varied in the following sequence: $\mathrm{AES}>\mathrm{SDBS}>\mathrm{SDS} \approx$ Triton $\mathrm{X}-100>$ Tween 80 . This indicated that anionic surfactants had greater potential for mobilizing arsenic from sediment-packed columns.

\subsection{SEP}

According to the bonding affinity with sediment, arsenic in the sediment can be divided into five fractions: F1, nonspecifically adsorbed fraction; F2, specifically adsorbed fraction; F3, amorphous and poorly-crystalline hydrous iron and aluminum oxides associated fraction; F4, crystallized hydrous iron and aluminum oxides associated fraction; and $\mathrm{F} 5$ residual fraction. From F1 to F5, the bonding affinity of arsenic with sediment varies from weak to strong (Haus et al., 2008; Wenzel et al., 2001). Thus, arsenic fraction variations derived from SEP analysis are significant for assessing the ability of surfactants to mobilize arsenic with different association affinities in sediment. The SEP analysis is also useful to specify to what extent arsenic in the sediment could be mobilized by surfactants.

Table 1 - Fractions of arsenic in the sediment before and after treatment by $100 \mathrm{mg} / \mathrm{L}$ surfactants. The concentration of sediment was $40 \mathrm{~g} / \mathrm{L}$.

\begin{tabular}{lccccc} 
Sediment & \multicolumn{5}{c}{ Fractions of arsenic (mg/kg) } \\
\cline { 2 - 6 } & F1 & F2 & F3 & F4 & F5 \\
\hline Raw & 0.63 & 26.12 & 111.44 & 33.79 & 11.21 \\
SDBS-Sed & 0.59 & 22.59 & 107.93 & 33.96 & 14.08 \\
SDS-Sed & 0.58 & 23.49 & 110.70 & 33.26 & 14.74 \\
AES-Sed & 0.49 & 16.98 & 86.63 & 29.31 & 12.92 \\
Triton-Sed & 0.70 & 25.76 & 110.15 & 33.37 & 11.72 \\
Tween-Sed & 0.49 & 25.18 & 111.21 & 31.64 & 12.32 \\
\hline
\end{tabular}

As shown in Table 1, total arsenic content in the raw sediment was $183.19 \mathrm{mg} / \mathrm{kg}$, in which the F3 fraction, whose content was $111.44 \mathrm{mg} / \mathrm{kg}$, accounting for $60.83 \%$ of the total arsenic, was the most abundant fraction. It was followed by the F4 fraction, whose content was $33.79 \mathrm{mg} / \mathrm{kg}$ and accounted for $18.45 \%$ of the total arsenic. The contents of the remaining three fractions were as follows from high to low: $\mathrm{F} 2,26.12 \mathrm{mg} / \mathrm{kg}$, accounting for $14.26 \%$; F5, $11.21 \mathrm{mg} / \mathrm{kg}$, accounting for $6.12 \%$; the content of the F1 fraction was the lowest, namely $0.63 \mathrm{mg} / \mathrm{kg}$, accounting for $0.34 \%$. Generally, the residual arsenic fraction is the most difficult fraction to mobilize, thus the mobility and environmental risks are at the lowest level. However, the other four fractions of arsenic could be released from sediments, and their contents were the highest, accounting for $93.88 \%$ of total arsenic. Besides, the total content of F1 and F2 in the sediment was $26.75 \mathrm{mg} / \mathrm{kg}$, accounting for $14.60 \%$ of the total amount of arsenic in sediment. Arsenic species in F1 and F2 fractions have been considered to be dissolvable fractions, which are regarded as having the greatest mobility.

Arsenic in F1 is mainly adsorbed to the sediment surface through electrostatic attraction, which could be easily replaced by the introduction of surfactants. However, the amount of F1 arsenic remained nearly steady. This was mainly because the equilibrium between mobilization and adsorption had been achieved.

Contents of arsenic in F2 showed an obvious decrease in all five surfactant solutions. The sequence of the ability of surfactants to mobilize F2 arsenic was as follows: AES > SDB $>$ SSDS > Tween $80>$ Triton X-100. Moreover, F2 was the fraction in which arsenic was mobilized most by the four surfactants SDBS, SDS, Triton X-100 and Tween 80. However, the presence of AES also caused a measurable release of arsenic in more stable fractions: F3 and F4. This suggested that the anionic surfactant AES had great potential to mobilize more stably associated arsenic from sediment, indicating its greater environmental risk than the other four surfactants.

\subsection{SPE experiments}

Generally, arsenic exists in the environment in two oxidation states (As(V) and As(III)) and organically associated arsenic compounds, among which As(III) is the most mobile and toxic species (Cullen and Reimer, 1989). Thus, to assess the environmental risks caused by arsenic mobilization by surfactants, it was essential to investigate the speciation of arsenic that was mobilized and released to the environment by surfactants. In the present study, different mobilized arsenic species were separated using the SPE method. The results are listed in Table 2. In batch experiments, mobilized As(III) accounted for $17.63 \%-33.15 \%$ of the mobilized total arsenic. The highest concentration was from the AES system, reaching $19.82 \mu \mathrm{g} / \mathrm{L}$. The mobilization capability of surfactants for As(III) followed the sequence: SDBS > SDS > Tween 80 > AES > Triton X-100. Arsenate was the predominant species mobilized from sediment by surfactants in batch tests, accounting for $54.82 \%$ $74.96 \%$. In addition, the mobilized organically associated arsenic was $5.93 \%-12.03 \%$ of the total arsenic mobilized by surfactants. The release of organically associated arsenic was mainly due to the solubilization of organic matters in the 
Table 2 - Speciation of arsenic released by surfactants in batch and column tests. For the batch tests, the concentration of surfactants and sediment was $50 \mathrm{mg} / \mathrm{L}$ and $40 \mathrm{~g} / \mathrm{L}$, respectively. For the column experiments, $15 \mathrm{~mL}$ samples were taken at $160 \mathrm{hr}$ from the column study described in

\begin{tabular}{lllllc}
\multicolumn{2}{c}{ Reaction system } & \multicolumn{4}{c}{ Speciation of arsenic $(\mu \mathrm{g} / \mathrm{L})$} \\
\cline { 3 - 6 } & & As (Total) & As(III) & As(V) & Organic-As \\
\hline \multirow{2}{*}{ Batch } & SDBS & 21.78 & 7.22 & 11.94 & 2.62 \\
& SDS & 19.57 & 5.78 & 11.87 & 1.92 \\
& AES & 82.61 & 19.82 & 55.73 & 7.06 \\
& Triton X-100 & 17.19 & 3.03 & 12.84 & 1.32 \\
& Tween 80 & 20.23 & 5.40 & 13.63 & 1.20 \\
Column & SDBS & 14.44 & 2.75 & 11.09 & 0.60 \\
& SDS & 13.53 & 2.68 & 10.51 & 0.34 \\
& AES & 16.29 & 3.97 & 11.41 & 0.91 \\
& Triton X-100 & 9.50 & 2.93 & 6.18 & 0.39 \\
& Tween 80 & 11.69 & 2.81 & 7.78 & 1.10
\end{tabular}

sediment by surfactants. In addition to arsenic speciation analysis in batch tests, samples taken from the column study described in Section 2.2 at $160 \mathrm{hr}$ were also used for speciation study. The release of As(III) by the flow-through of surfactant solutions reached $19.04 \%-32.38 \%$ of the total release of arsenic. The mobilization of $\mathrm{As}(\mathrm{V})$ and organically associated arsenic accounted for $65.05 \%-77.68 \%$ and $2.51 \%-9.41 \%$, respectively.

\subsection{Mobilization of iron from the sediment by surfactants}

It has been well demonstrated that arsenic in the environment is mainly adsorbed onto iron-bearing sediment, forming surface precipitates or ternary complexes with organic matters (As-Fe-OM) (Bose and Sharma, 2002; Horneman et al., 2004; Wang et al., 2012). Dissolution release of iron from sediment has been regarded as one important mechanism for arsenic mobilization (Nickson et al., 2000; Polizzotto et al., 2008). In the present study, the correlation between arsenic and iron mobilization was investigated to further elucidate arsenic release mechanisms. As shown in Fig. 6, the presence of the five surfactants caused significant release of iron from sediment. Based on the potential of surfactants to elute heavy metals from sediments, mechanisms related to mobilization of iron from sediment could include: (1) reduction of the interfacial tension between sediment surface and solution; (2) solubilization of iron by surfactant micelles; (3) adsorption exchange of adsorbed surfactants with iron on the sediment surface (Mulligan et al., 2001b; Nivas et al., 1996; Raatz and Hartel, 1998). With regard to the simultaneous mobilization of arsenic and iron from sediment by surfactants, the correlation analysis is also given in Fig. 6. For the surfactants SDBS, SDS, Triton X-100 and Tween 80 , arsenic mobilization correlated linearly $\left(R^{2}>0.91\right)$ with iron mobilization, which to some extent indicated that mobilization of arsenic was enhanced by the mobilization of iron. For the anionic surfactant AES, the relationship between mobilization of arsenic and iron could be divided into two linear stages, with the inflection occurring at the system with $20 \mathrm{mg} / \mathrm{L}$ AES. This could be attributed to the increasing release of stably associated As-Fe complexes with the increase of AES concentration, especially when the concentration was greater than $20 \mathrm{mg} / \mathrm{L}$.

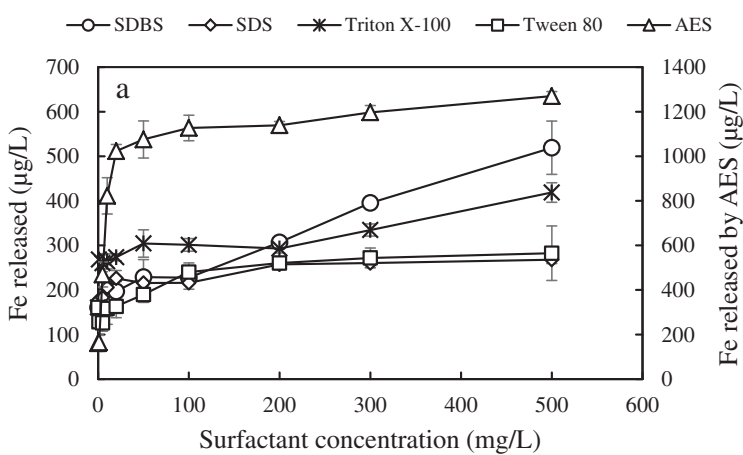

$\circ$ SDBS $\diamond$ SDS $\times$ Triton X-100 $\square$ Tween $80 \triangle$ AES

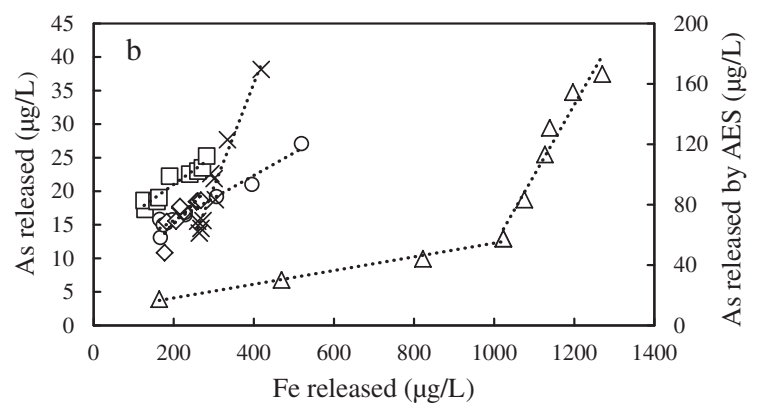

Fig. 6 - Mobilization of iron (a) by surfactants and the correlation between the mobilization of arsenic (b) from sediment by surfactants with different concentrations at $\mathrm{pH} 7.0$ and $25^{\circ} \mathrm{C}$. The concentration of surfactant varied from 0 to $500 \mathrm{mg} / \mathrm{L}$ and the dosage of sediment was $50 \mathrm{~g} / \mathrm{L}$.

\subsection{Speciation of arsenic and iron in dialysis and ultrafiltration experiments}

The good correlation between arsenic and iron mobilization by surfactants primarily indicated that mobilization of arsenic

Table 3-Dialysis and ultrafiltration of arsenic and iron mobilized from sediment by surfactants. Samples used for dialysis were prepared using $40 \mathrm{~g} / \mathrm{L}$ sediment and $500 \mathrm{mg} / \mathrm{L}$ surfactants. Samples for ultrafiltration were prepared using $\mathbf{5 0} \mathrm{g} / \mathrm{L}$ sediment and $\mathbf{5 0} \mathrm{mg} / \mathrm{L}$ surfactants.

\begin{tabular}{|c|c|c|c|c|}
\hline \multirow[t]{2}{*}{ Reaction system } & \multicolumn{2}{|c|}{$\begin{array}{l}\text { Before dialysis } \\
\qquad(\mu \mathrm{g} / \mathrm{L})\end{array}$} & \multicolumn{2}{|c|}{$\begin{array}{l}\text { After dialysis } \\
(\mu \mathrm{g} / \mathrm{L})\end{array}$} \\
\hline & Arsenic & Iron & Arsenic & Iron \\
\hline SDBS & 64.38 & 384.27 & 13.85 & 93.39 \\
\hline SDS & 28.58 & 276.01 & 8.7 & 70.16 \\
\hline AES & 170.50 & 1538.13 & 36.03 & 428.33 \\
\hline Triton X-100 & 24.28 & 264.01 & 5.51 & 27.21 \\
\hline Tween 80 & 25.90 & 231.46 & 5.41 & 32.44 \\
\hline \multirow[t]{2}{*}{ Reaction system } & \multicolumn{2}{|c|}{$\begin{array}{c}\text { Before } \\
\text { ultrafiltration } \\
(\mu \mathrm{g} / \mathrm{L})\end{array}$} & \multicolumn{2}{|c|}{$\begin{array}{c}\text { After } \\
\text { ultrafiltration } \\
(\mu \mathrm{g} / \mathrm{L})\end{array}$} \\
\hline & Arsenic & Iron & Arsenic & Iron \\
\hline SDBS & 21.36 & 548.80 & 18.01 & 449.89 \\
\hline SDS & 8.38 & 164.84 & 7.81 & 152.29 \\
\hline AES & 47.31 & 837.62 & 38.77 & 710.97 \\
\hline Triton X-100 & 9.07 & 123.12 & 8.72 & 112.60 \\
\hline Tween 80 & 7.65 & 161.19 & 7.08 & 142.18 \\
\hline
\end{tabular}


could be enhanced by the mobilization of iron. However, the quantitative relationship between the mobilization of iron and the mobilization of arsenic is unclear. To quantitatively specify the mechanism of the mobilization of arsenic by surfactants, fractions of arsenic and iron from batch mobilization experiments were separated using dialysis and ultrafiltration. In the experiments, dissolved arsenic and iron passed through the dialysis and ultrafiltration membrane, and organically associated arsenic and iron (OM-As and OM$\mathrm{Fe}$ ) and the ternary complex As-Fe-OM were retained in the dialysis bag or on the ultrafiltration membrane (Sharma et al., 2011). As shown in Table 3, $20.89 \%-30.44 \%$ of total arsenic and $10.31 \%-27.85 \%$ of total iron remained in the dialysis bag after the dialysis experiment, suggesting that these parts of arsenic and iron mobilized by $500 \mathrm{mg} / \mathrm{L}$ surfactants were in organically complexed fractions. Similarly, as can be seen from Table 3, 3.86\%-18.04\% of total arsenic and $7.61 \%-18.02 \%$ of total iron mobilized by surfactants were in organically associated fractions. Therefore, arsenic released from sediment by all five surfactants mainly presented as dissolved fractions (approximately 70\%), which consisted of As(V) and As(III) according to the SPE separation analysis. In addition, surfactants played an important role in solubilization of organic matters in sediment, which could result in the release of arsenic in the fractions of As-OM and As-Fe-OM.

\section{Conclusions}

Surfactants were found to have great potential for mobilizing arsenic from contaminated sediment in both batch and flowthrough systems. The mobilization increased with the increase of surfactant concentrations and $\mathrm{pH}$. Metal ions mainly reduced arsenic mobilization by surfactants. Mobilization of arsenic increased significantly with time over the first $8 \mathrm{hr}$ and then reached equilibrium gradually. The ability of surfactants to release arsenic from packed columns followed the sequence: AES $>$ SDBS $>$ SDS $\approx$ Triton $\mathrm{X}-100>$ Tween 80 . The five surfactants mainly mobilized the specifically adsorbed arsenic, in which $\mathrm{As}(\mathrm{V})$ and $\mathrm{As}(\mathrm{III})$ accounted for $65.05 \%-77.68 \%$ and $2.51 \%-$ $9.41 \%$. Surfactants could mobilize iron from sediment and the mobilization of arsenic was positively correlated with the mobilization of iron, indicating that arsenic mobilization could be enhanced by the mobilization of iron by surfactants. Dialysis and ultrafiltration suggested that approximately $70 \%$ of total mobilized arsenic was in dissolved fractions. Potential mechanisms for surfactant mobilization of arsenic may include: the adsorption of surfactants on sediment, resulting in the exchange and mobilization of arsenic; the release of iron from sediment by surfactants, leading to the release of Fe-As complexes; and the solubilization of organic matters by surfactants, causing the release of arsenic in the fractions of $\mathrm{OM}-\mathrm{As}$ and/or As-Fe-OM complexes.

\section{Acknowledgments}

This work was supported by the National Natural Science Foundation of China (Nos. 41273123 and 41473113) and the special fund from the State Key Joint Laboratory of
Environment Simulation and Pollution Control (Research Center for Eco-Environmental Sciences, Chinese Academy of Sciences) (No. 14Z02ESPCR).

\section{R E F E R E N C E S}

Basar, C.A., Karagunduz, A., Cakici, A., Keskinler, B., 2004. Removal of surfactants by powdered activated carbon and microfiltration. Water Res. 38 (8), 2117-2124.

Bauer, M., Blodau, C., 2006. Mobilization of arsenic by dissolved organic matter from iron oxides, soils and sediments. Sci. Total Environ. 354 (2-3), 179-190.

Bennie, D.T., Sullivan, C.A., Lee, H.B., Peart, T.E., Maguire, R.J., 1997. Occurrence of alkylphenols and alkylphenol mono- and diethoxylates in natural waters of the Laurentian Great Lakes basin and the upper St. Lawrence River. Sci. Total Environ. 193 (3), 263-275

Bose, P., Sharma, A., 2002. Role of iron in controlling speciation and mobilization of arsenic in subsurface environment. Water Res. 36 (19), 4916-4926.

Camacho, L., Cruz, A., Castro, R., Casals, C., Pérez-Gil, J., 1996. Effect of $\mathrm{pH}$ on the interfacial adsorption activity of pulmonary surfactant. Colloids Surf., B 5 (6), 271-277.

Céspedes, R., Lacorte, S., Ginebreda, A., Barceló, D., 2008. Occurrence and fate of alkylphenols and alkylphenol ethoxylates in sewage treatment plants and impact on receiving waters along the Ter River (Catalonia, NE Spain). Environ. Pollut. 153 (2), 384-392.

Clara, M., Scharf, S., Scheffknecht, C., Gans, O., 2007. Occurrence of selected surfactants in untreated and treated sewage. Water Res. 41 (19), 4339-4348.

Cullen, W.R., Reimer, K.J., 1989. Arsenic speciation in the environment. Chem. Rev. 89 (4), 713-764.

Garcia, S.A., Alonso, R.P., Santos, F.F., 2010. Distribution and mobility of arsenic in soils of a mining area (Western Spain). Sci. Total Environ. 408 (19), 4194-4201.

Guo, H.M., Zhang, B., Zhang, Y., 2011. Control of organic and iron colloids on arsenic partition and transport in high arsenic groundwaters in the Hetao basin, Inner Mongolia. Appl. Geochem. 26 (3), 360-370.

Haus, K.L., Hooper, R.L., Strumness, L.A., Mahoney, J.B., 2008. Analysis of arsenic speciation in mine contaminated lacustrine sediment using selective sequential extraction, HR-ICPMS and TEM. Appl. Geochem. 23 (4), 692-704.

Horneman, A., van Geen, A., Kent, D.V., Mathe, P.E., Zheng, Y., Dhar, R.K., et al., 2004. Decoupling of As and Fe release to Bangladesh groundwater under reducing conditions. Part I: evidence from sediment profiles1. Geochim. Cosmochim. Acta 68 (17), 3459-3473.

Huang, C., Van Benschoten, J.E., 2000. Effect of pH on adsorption of sulfonated surfactants to a sandy soil. Environ. Eng. Sci. 17 (3), 159-168.

Islam, F.S., Gault, A.G., Boothman, C., Polya, D.A., Charnock, J.M., Chatterjee, D., et al., 2004. Role of metal-reducing bacteria in arsenic release from Bengal delta sediments. Nature 430 (6995), 68-71.

Lara-Martín, P.A., Petrovic, M., Gómez-Parra, A., Barceló, D., González-Mazo, E., 2006. Presence of surfactants and their degradation intermediates in sediment cores and grabs from the Cadiz Bay area. Environ. Pollut. 144 (2), 483-491.

Lara-Martín, P.A., Gómez-Parra, A., González-Mazo, E., 2008. Sources, transport and reactivity of anionic and non-ionic surfactants in several aquatic ecosystems in SW Spain: a comparative study. Environ. Pollut. 156 (1), 36-45.

Le, X.C., Yalcin, S., Ma, M., 2000. Speciation of Submicrogram per liter levels of arsenic in water: on-site species separation 
integrated with sample collection. Environ. Sci. Technol. 34 (11), 2342-2347.

Li, N., Thomas, R.K., Rennie, A.R., 2012. Effect of pH, surface charge and counter-ions on the adsorption of sodium dodecyl sulfate to the sapphire/solution interface. J. Colloid Interface Sci. 378 (1), 152-158.

Liang, C., Wang, X., Peng, X., 2016. Arsenic retention and transport behavior in the presence of typical anionic and nonionic surfactants. J. Environ. Sci. 39, 249-258.

Marcomini, A., Pojana, G., Sfriso, A., Alonso, J.M.Q., 2000. Behavior of anionic and nonionic surfactants and their persistent metabolites in the Venice lagoon, Italy. Environ. Toxicol. Chem. 19 (8), 2000-2007.

Mladenov, N., Zheng, Y., Miller, M.P., Nemergut, D.R., Legg, T., Simone, B., et al., 2010. Dissolved organic matter sources and consequences for iron and arsenic mobilization in Bangladesh aquifers. Environ. Sci. Technol. 44 (1), 123-128.

Mulligan, C.N., 2005. Environmental applications for biosurfactants. Environ. Pollut. 133 (2), 183-198.

Mulligan, C.N., 2009. Recent advances in the environmental applications of biosurfactants. Curr. Opin. Colloid Interface Sci. 14 (5), 372-378.

Mulligan, C.N., Yong, R.N., Gibbs, B.F., 2001a. Surfactant-enhanced remediation of contaminated soil: a review. Eng. Geol. 60 (1-4), 371-380.

Mulligan, C.N., Yong, R.N., Gibbs, B.F., 2001b. Heavy metal removal from sediments by biosurfactants. J. Hazard. Mater. 85 (1-2), 111-125.

Mushtaq, M., Tan, I.M., Rashid, U., Sagir, M., Mumtaz, M., 2015. Effect of $\mathrm{pH}$ on the static adsorption of foaming surfactants on Malaysian sandstone. Arab. J. Geosci. 8 (10), 8539-8548.

Nickson, R.T., McArthur, J.M., Ravenscroft, P., Burgess, W.G., Ahmed, K.M., 2000. Mechanism of arsenic release to groundwater, Bangladesh and West Bengal. Appl. Geochem. 15 (4), 403-413.

Nivas, B.T., Sabatini, D.A., Shiau, B.-J., Harwell, J.H., 1996. Surfactant enhanced remediation of subsurface chromium contamination. Water Res. 30 (3), 511-520.

Polizzotto, M.L., Kocar, B.D., Benner, S.G., Sampson, M., Fendorf, S., 2008. Near-surface wetland sediments as a source of arsenic release to ground water in Asia. Nature 454 (7203), 505-508.

Raatz, S., Hartel, G., 1998. Extraction behaviour of heavy metals. Tenside Surfact. Deterg. 35 (3), 170-175.

Rao, P.H., He, M., 2006. Adsorption of anionic and nonionic surfactant mixtures from synthetic detergents on soils. Chemosphere 63 (7), 1214-1221.

Rodríguez-Cruz, M.S., Sanchez-Martin, M.J., Sanchez-Camazano, M., 2005. A comparative study of adsorption of an anionic and a non-ionic surfactant by soils based on physicochemical and mineralogical properties of soils. Chemosphere 61 (1), 56-64.

Rosen, M.J., Kunjappu, J.T., 2012. Surfactants and Interfacial Phenomena. John Wiley \& Sons.

Routh, J., Bhattacharya, A., Saraswathy, A., Jacks, G., Bhattacharya, P., 2007. Arsenic remobilization from sediments contaminated with mine tailings near the Adak mine in Vasterbotten district (northern Sweden). J. Geochem. Explor. 92 (1), 43-54.

Rubinos, D., Iglesias, L., Devesa-Rey, R., Diaz-Fierros, F., Barral, M.T., 2010. Arsenic release from river sediments in a gold-mining area (Anllons River basin, Spain): effect of time, $\mathrm{pH}$ and phosphorous concentration. Eur. J. Mineral. 22 (5), 665-678.

Rubio-Campos, B.E., Cano-Aguilera, I., Aguilera-Alvarado, A.F., De la Rosa, G., Soriano-Perez, S.H., 2010. Factors controlling the release of arsenic from mining tailings. Environ. Toxicol. 132, 55-66.
Sanchez-Martin, M.J., Dorado, M.C., del Hoyo, C., Rodriguez-Cruz, M.S., 2008. Influence of clay mineral structure and surfactant nature on the adsorption capacity of surfactants by clays. J. Hazard. Mater. 150 (1), 115-123.

Shalaby, M.N., 2007. Behavior study of some commercial nonionic compounds in comparison with anionic surfactant. Chem. Eng. Commun. 194 (4), 464-476.

Sharma, P., Rolle, M., Kocar, B., Fendorf, S., Kappler, A., 2011. Influence of natural organic matter on as transport and retention. Environ. Sci. Technol. 45 (2), 546-553.

Shen, Y.H., 2000. Sorption of non-ionic surfactants to soil: the role of soil mineral composition. Chemosphere 41 (5), 711-716.

Sugihara, G., Nagadome, S., Oh, S.W., Ko, J.S., 2008. A review of recent studies on aqueous binary mixed surfactant systems. J. Oleo Sci. 57 (2), 61-92.

Wang, W., Kwak, J.C.T., 1999. Adsorption at the alumina-water interface from mixed surfactant solutions. Colloids Surf. A Physicochem. Eng. Asp. 156 (1-3), 95-110.

Wang, S.L., Mulligan, C.N., 2009a. Enhanced mobilization of arsenic and heavy metals from mine tailings by humic acid. Chemosphere 74 (2), 274-279.

Wang, S.L., Mulligan, C.N., 2009b. Effect of natural organic matter on arsenic mobilization from mine tailings. J. Hazard. Mater. 168 (2-3), 721-726.

Wang, S.L., Mulligan, C.N., 2009c. Arsenic mobilization from mine tailings in the presence of a biosurfactant. Appl. Geochem. 24 (5), 928-935.

Wang, Y., Sikora, S., Kim, H., Dubey, B., Townsend, T., 2012. Mobilization of iron and arsenic from soil by construction and demolition debris landfill leachate. Waste Manag. 32 (5), 925-932.

Wenzel, W.W., Kirchbaumer, N., Prohaska, T., Stingeder, G., Lombi, E., Adriano, D.C., 2001. Arsenic fractionation in soils using an improved sequential extraction procedure. Anal. Chim. Acta 436 (2), 309-323.

West, C.C., Harwell, J.H., 1992. Surfactants and subsurface remediation. Environ. Sci. Technol. 26 (12), 2324-2330.

Yalcin, S., Le, X.C., 2001. Speciation of arsenic using solid phase extraction cartridges. J. Environ. Monit. 3 (1), 81-85.

Yang, K., Zhu, L.Z., Xing, B.S., 2007. Sorption of sodium dodecylbenzene sulfonate by montmorillonite. Environ. Pollut. 145 (2), 571-576.

Yang, G.P., Chen, Q.A., Li, X.X., Cao, X.Y., 2010. Study on the sorption behaviors of Tween-80 on marine sediments. Chemosphere 79 (11), 1019-1025.

Ying, G.G., 2006. Fate, behavior and effects of surfactants and their degradation products in the environment. Environ. Int. 32 (3), 417-431.

Ying, G.-G., Williams, B., Kookana, R., 2002. Environmental fate of alkylphenols and alkylphenol ethoxylates-a review. Environ. Int. 28 (3), 215-226.

Zgoła-Grześkowiak, A., Grześkowiak, T., Rydlichowski, R., Łukaszewski, Z., 2009. Determination of nonylphenol and short-chained nonylphenol ethoxylates in drain water from an agricultural area. Chemosphere 75 (4), 513-518.

Zhang, X.L., Penfold, J., Thomas, R.K., Tucker, I.M., Petkov, J.T., Bent, J., et al., 2011. Adsorption behavior of hydrophobin and hydrophobin/surfactant mixtures at the solid-solution interface. Langmuir 27 (17), 10464-10474.

Zhang, W., Zhang, Y.T., Taniyasu, S., Yeung, L.W.Y., Lam, P.K.S., Wang, J.S., et al., 2013. Distribution and fate of perfluoroalkyl substances in municipal wastewater treatment plants in economically developed areas of China. Environ. Pollut. 176, 10-17. 